\title{
Feasibility of electromagnetic soil heating using magnetic nanoparticle-coated geotextiles
}

\author{
IJUNG KIM*, CAROLINE BEST† and SEUNGHEE KIM $\ddagger$
}

\begin{abstract}
This paper reports a new way of soil heating using a woven and a non-woven geotextile coated with magnetic nanoparticles (MNPs) that generate heat when exposed to a magnetic field. The MNPs were synthesised in the presence of the geotextile, creating and simultaneously coating the MNPs onto the geotextile. The fixation of MNPs on the geotextile was confirmed by direct observation by way of scanning electromagnetic images and an induction heating test. When the prepared geotextile was placed inside a soil medium, heat was generated immediately as the geotextile was exposed to a high-frequency alternating magnetic field, subsequently transferring heat from the MNP-coated geotextile to the surrounding soil. The soil heating performance was greater with the non-woven geotextile than with the woven one, which implies a better capacity to retain the MNPs with a rough surface. However, the effect of different soil types (sand and clay) on heating performance was insignificant. A follow-up study on the heat transfer on a field scale will provide a practical strategy for field application. Overall, the innovative heating method can potentially provide additional functionality to geotextiles as an attractive option for soil heating.
\end{abstract}

KEYWORDS: geotextiles, geomembranes \& geogrids

Published with permission by the ICE under the CC-BY 4.0 license. (http://creativecommons.org/licenses/by/4.0/)

\section{INTRODUCTION}

Advances in the synthesis of magnetic nanoparticles (MNPs) and their potential for electromagnetic heating are attracting attention from various fields. For instance, the electromagnetic heating of MNPs has been actively studied in the biomedical area of hypothermia therapy (Jordan et al., 1999). Moreover, such heating has also been used for improvement of materials (Zhang et al., 2018; Zhu et al., 2018a), underground oil exploration and recovery (Bera \& Babadagli, 2015; Hu et al., 2017, Zhu et al., 2018b), and environmental treatment (Rodriguez-Chueca et al., 2014; Liew et al., 2018). Electromagnetic heating may have an advantage over conventional heating methods, primarily due to its high-heating rate within a short period and its non-contact nature by way of electromagnetic irradiation. Nonetheless, the significant potential of electromagnetic heating for many other applications remains untapped, including geotechnical engineering and heating of substrata.

Soil heating does have several beneficial applications already, including soil remediation (Heron et al., 1998; Varanasi et al., 2007; Roland et al., 2008; Falciglia et al., 2013; Rodriguez-Chueca et al., 2014), soil sterilisation (Trevors, 1996; Javaid et al., 2008) and cultivation (Benli \& Durmus, 2009; Zhang et al., 2015; Wang et al., 2017). For these purposes, an environmentally applicable heating method is desirable.

Recently, soil heating has also garnered emerging attention from the energy-geotechnics field, for investigation such

Manuscript received 6 July 2019; first decision 21 October 2019; accepted 22 October 2019.

Published online at www.geotechniqueletters.com on 10 February 2020.

*Department of Civil Engineering, Hongik University, Seoul, Republic of Korea (Orcid:0000-0002-4148-2785).

†Greenman-Pederson, Inc., Albany, NY, USA.

tDepartment of Civil and Environmental Engineering, University of Nebraska-Lincoln, Omaha, NE, USA

(Orcid:0000-0003-0386-3007). as heat transfer from an implemented heat exchanger in soil and the ensuing thermo-mechanical response of soils (Coccia et al., 2013, Stewart et al., 2014a, Carpenter et al., 2015), the heat transfer from nearby structures (Stewart et al., 2014b) and the use of electrokinetic geosynthetics (Glendinning et al., 2005). Previously, soil heating was carried out by the installation and operation of a heating source, circulation of fluid through a closed-loop pipe and heat transfer to and from the surroundings (Omer, 2008). Recently, heating of MNPs has been proven competitive and effective regarding its rapidity. Moreover, localised heating can easily be implemented with a relatively simple system. Therefore, the potential of MNP heating is worth investigating as an alternative to conventional soil heating methods, aiming for a simpler system without direct contact with soils.

Geotextiles are permeable fabrics and have the ability to separate, filter, reinforce, protect or drain when associated with soils. For this reason, geotextiles have been widely used for various geotechnical engineering projects. This study explores the potential of non-contact soil heating using a MNP-coated geotextile and electromagnetic heating. First, MNPs were synthesised together with a selected geotextile to coat the geotextile with nanoparticles. Once the coating was achieved, the MNP-coated geotextile was embedded inside a soil specimen for the investigation of soil heating. The heating performance of the MNP-coated geotextile and the surrounding soil medium through electromagnetic heating was examined using a small-scale testing set-up. Complementary simulation was conducted to inversely assess the heating rate of the MNP-coated geotextile and surrounding soils. The materials and experimental methods are presented in the following section.

MATERIALS AND SYNTHESIS METHODS

The chemical co-precipitation method was used to synthesise MNPs and to coat them onto the geotextiles simultaneously. 
The geotextiles used in this study were lightweight nonwoven polypropylene geotextiles (Mirafi $140 \mathrm{~N}$, Tencate) and woven polypropylene geotextiles (Mirafi 500X, Tencate). The dimensions of the tested geotextiles were $3 \times 10 \mathrm{~cm}$ (Fig. 1). To synthesise the MNPs, $2 \cdot 15 \mathrm{~g}$ of ferrous chloride tetrahydrate, $5.875 \mathrm{~g}$ of ferric chloride hexahydrate and $0 \cdot 125 \mathrm{~g}$ of citric acid monohydrate were dissolved in $100 \mathrm{ml}$ of distilled water. The citric acid was added to cover the nanoparticle surface as a surface protectant. A portion of the geotextile fabric immersed in the solution was heated, and on reaching $90^{\circ} \mathrm{C}, 25 \mathrm{ml}$ of ammonia hydroxide $(30 \%)$ was added to the solution. Next, the solution was maintained at $90^{\circ} \mathrm{C}$, stirred for $2 \mathrm{~h}$; then cooled to room temperature. Next, the MNP-coated geotextiles were air dried for $24 \mathrm{~h}$. The residual impurities were removed by rinsing in de-ionised (DI) water as required.

Once the above coating process was completed, the MNP-coated geotextile and the original uncoated geotextile were subjected to scanning electron microscopy (SEM, FEI Quanta 200) to conduct microscopic surface analysis. The SEM image shows an abundant and somewhat scattered coating of nanoparticles on the surface of the MNP-coated geotextile (Fig. 2(a)). This was very different from the untreated (original) surface (Fig. 2(b)). The geotextile appears to retain the surface coating without alteration of its structure during the process of MNP synthesis, which includes high-temperature heating in strong base (e.g. $\mathrm{pH}>8$ ).

In addition to the SEM analysis, the morphological and magnetic properties of the MNPs were analysed using transmission electron microscopy (TEM, Jeol JEM-2200FS) and vibrating sample magnetometry (VSM, VersaLab $3 \mathrm{~T}$ ), respectively. The synthesised MNPs had amorphous shapes, and the size of individual nanoparticles was less than $10 \mathrm{~nm}$ (Fig. 3). Their magnetic property and the potential for electromagnetic heating, were proven by a change in the magnetisation in response to the magnetic field (Fig. 4). When the magnetic field was removed $(0 \mathrm{Oe})$, the remaining magnetisation was $0.002 \mathrm{emu} / \mathrm{g}$, indicating the superparamagnetic property of the MNPs. The saturation magnetisation was around $4.36 \mathrm{emu} / \mathrm{g}$ at $5000 \mathrm{Oe}$. This value is much smaller than the reported value of bulk magnetite (Popplewell \& Sakhnini, 1995), and is probably due to the smaller size of the MNPs.

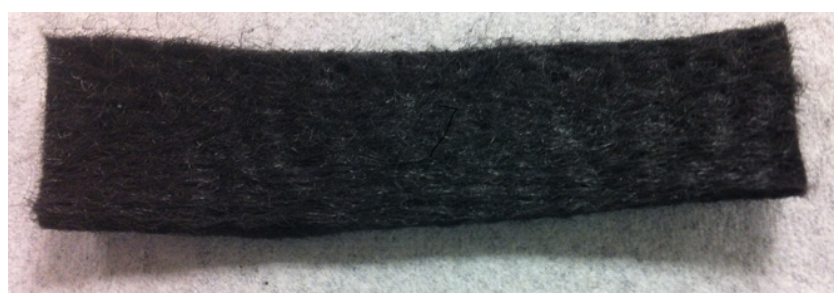

(a)

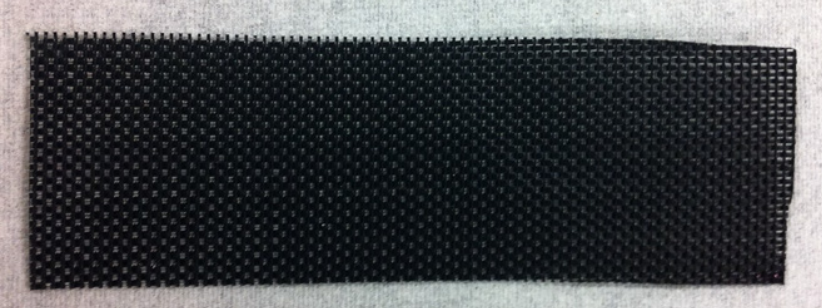

(b)

Fig. 1. Test geotextiles: (a) non-woven polypropylene geotextiles and (b) woven polypropylene geotextiles
EXPERIMENTAL SET-UP AND TESTING PROCEDURE

Before the main experiments, the heating of the MNPcoated geotextile was tested to confirm whether the geotextile could be heated on exposure to an alternating magnetic field (Fig. 5(a)). The electromagnetic heating was conducted using an induction heater ( $\mathrm{SH}-2 / 350$, Ultraflex) under the conditions of $332 \mathrm{kHz}, 9.8 \mathrm{~A}$ and $210 \mathrm{~V}$. The temperature of the MNP-coated geotextile increased to $60^{\circ} \mathrm{C}$ from room temperature in $1 \mathrm{~min}$, which attests to the successful MNP coating and heating.

Next, soil heating through electromagnetic heating of the MNP-coated geotextile and subsequent heat propagation using a specially designed testing set-up were investigated. For preparation of a test specimen, the MNP-coated geotextile was placed vertically in the middle of a cylindrical container $(3.2 \mathrm{~cm}$ inner diameter and $10 \mathrm{~cm}$ height $)$. After

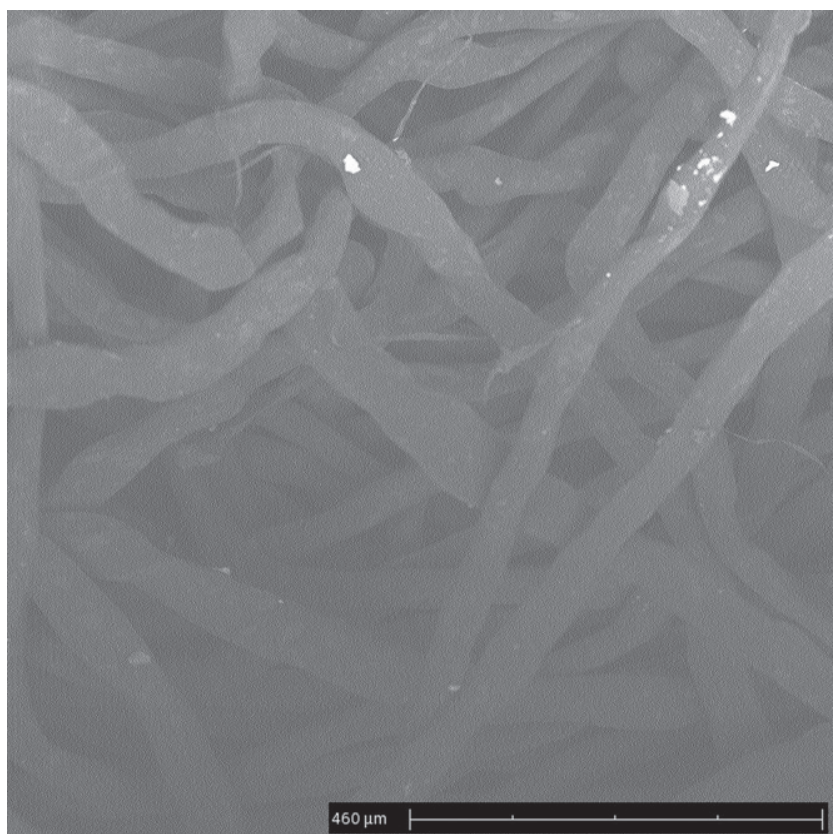

(a)

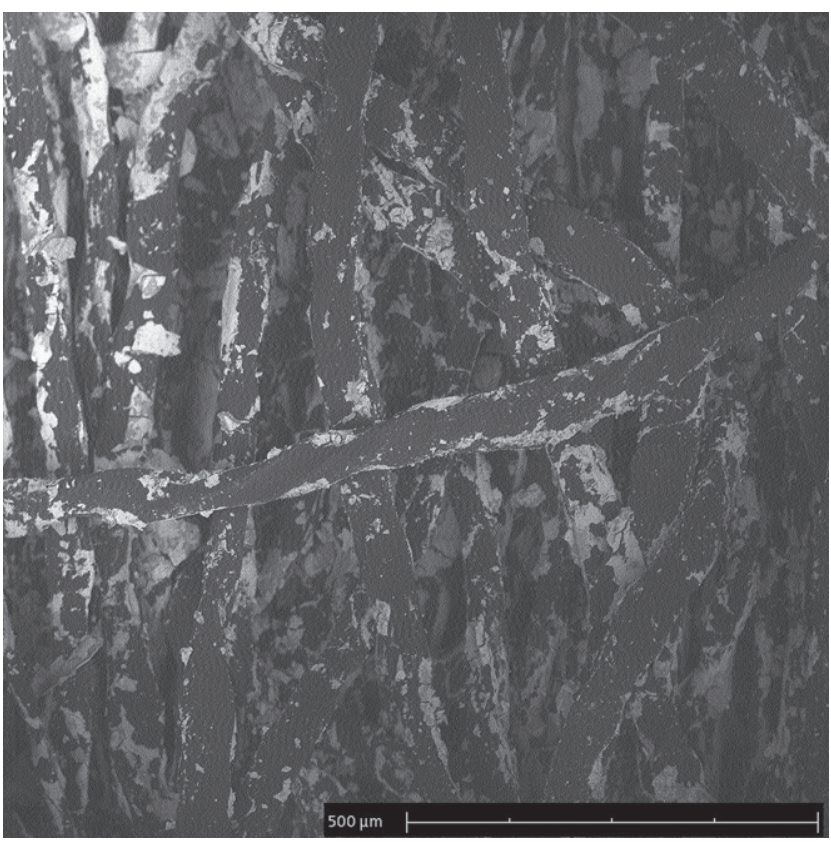

(b)

Fig. 2. SEM images of (a) original (uncoated) geotextile and (b) MNP-coated geotextile 


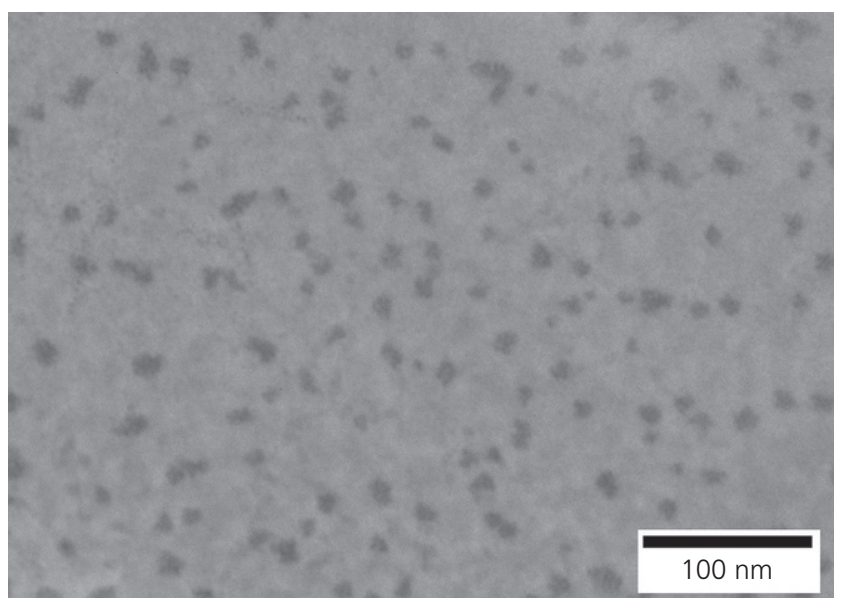

Fig. 3. TEM image of the MNPs created in this study

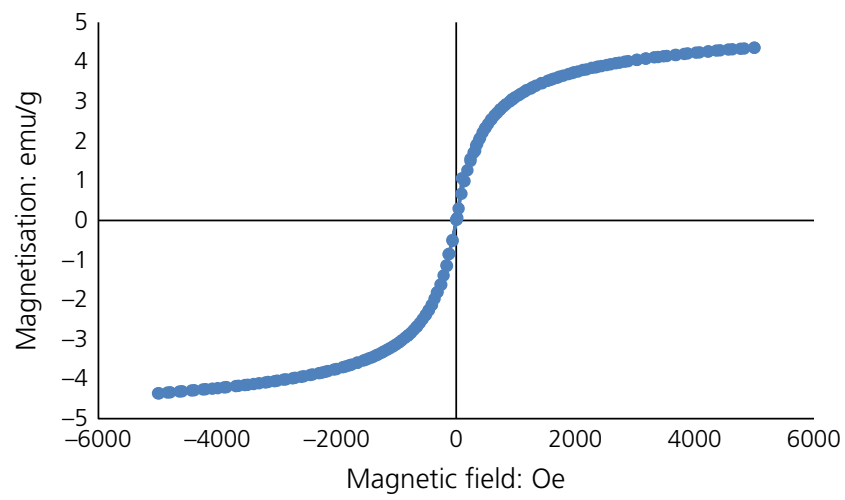

Fig. 4. Magnetisation curve of the MNPs

that, the remaining space of the cylindrical container was filled with soil, either sand (20-30 sand ASTM C 778) or clay (bentonite; Volclay CG-50), from the bottom to the top using the pluviation method (Fig. 5(b)). While filling, intermittent tapping to the sidewall of the container was applied to induce slight densification. Note that only dry soils were tested in this feasibility test. Properties of the soils are presented in Table 1. After that, the cylinder was placed inside the coil of the induction heater, which was turned on to produce an alternating magnetic field (Fig. 5(c)). The induction heater was turned on for a total of $300 \mathrm{~s}$ during the test. The temperature was monitored every $30 \mathrm{~s}$ at the surface of the soil using a non-contact infrared thermometer gun (Lasergrip 774, Etekcity).

\section{EXPERIMENTAL RESULTS AND DISCUSSION}

As mentioned above, two different soil types, sand and clay, were tested using geotextile with and without the embedded MNP coating. In case of no-MNP coating (i.e. as a control), the original geotextile was inserted into the soil and placed under the alternating magnetic field. The nearly constant temperature throughout the heating period demonstrates that both soil and geotextile exhibited negligible temperature change on exposure to the alternating magnetic field, confirming that little or no magnetic property existed in both soil and geotextile (Fig. 6(a)). On the contrary, with MNPs embedded in the geotextile, the apparent temperature rise was observed immediately, proving that coating of MNPs on the geotextile was successful. Noticeably, the initial heating rate during the first $30 \mathrm{~s}$ was quite extreme,

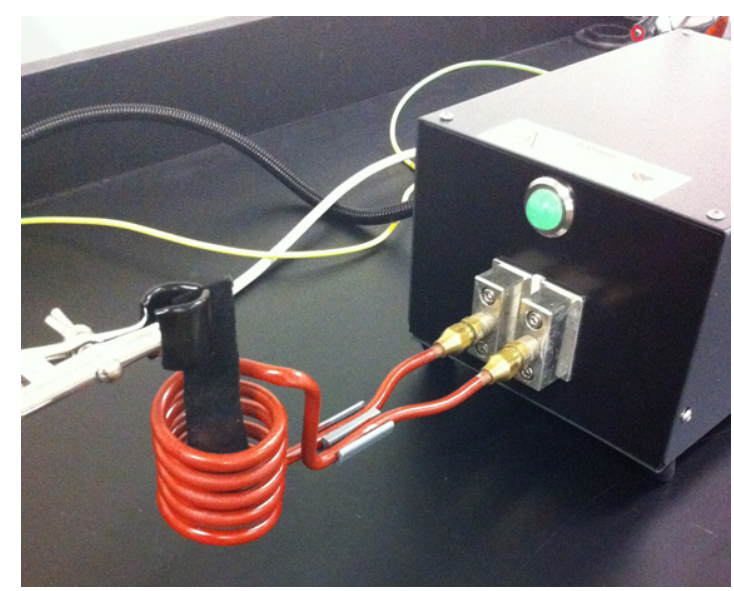

(a)

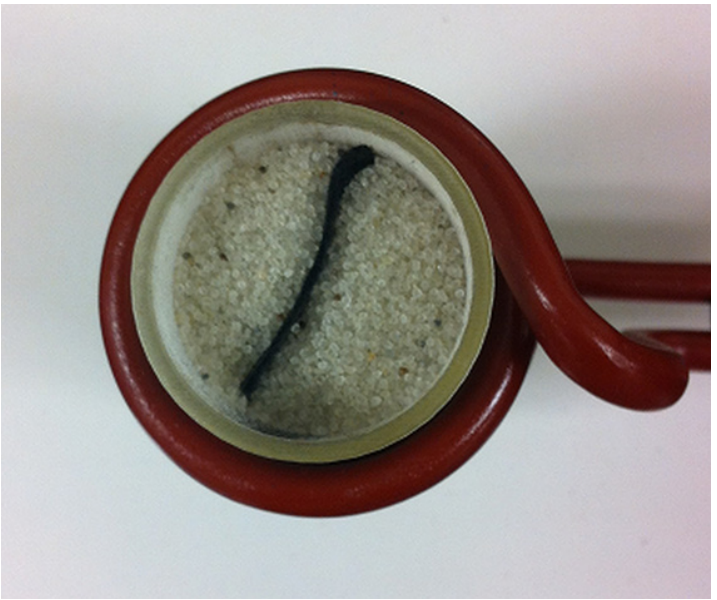

(b)

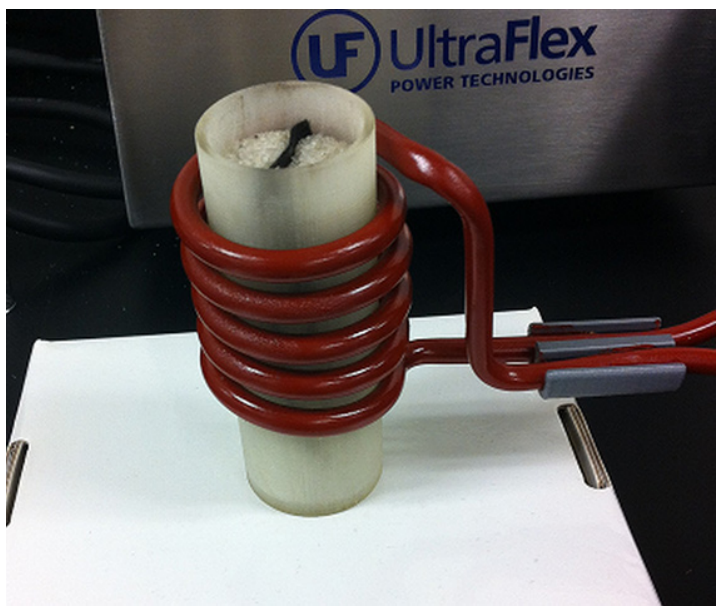

(c)

Fig. 5. Experimental set-up and testing: (a) heating test with MNP-coated geotextile only, (b) soil with inserted geotextile and (c) entire sample located inside the induction heater coil for the heating test

Table 1. Properties of the soils used in the experiment

\begin{tabular}{l|r|l}
\hline Property & Sand & Clay \\
\hline Dry unit weight, $\gamma_{\mathrm{d}}: \mathrm{kN} / \mathrm{m}^{3}$ & 13.75 & 8.41 \\
Void ratio, $e$ & 0.89 & 2.03 \\
Porosity, $n$ & 0.47 & 0.67 \\
\hline
\end{tabular}


which indicates the quick response with electromagnetic heating. The gradually diminishing heating rate may indicate that the number of MNPs coated on the geotextile might not

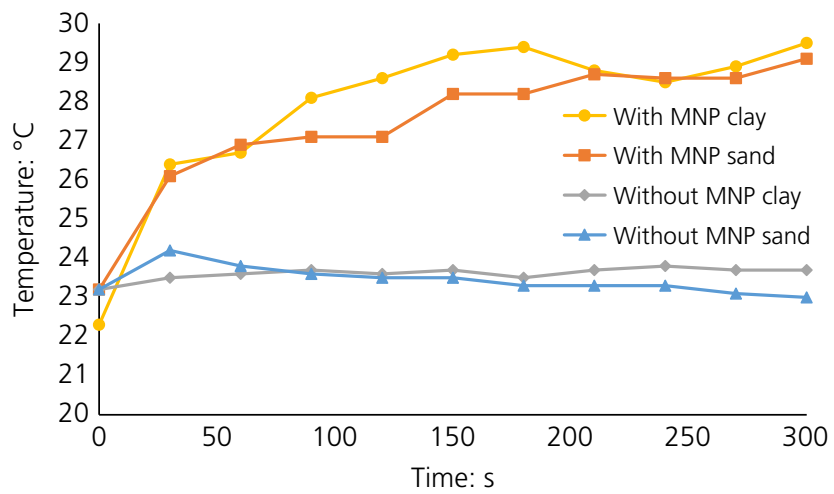

(a)

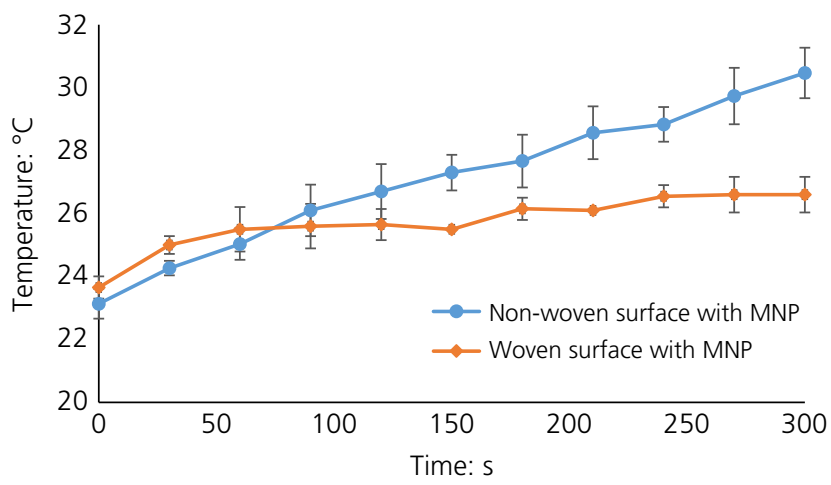

(b)

Fig. 6. Electromagnetic soil heating performance: (a) effect of different soil types and (b) different geotextile types

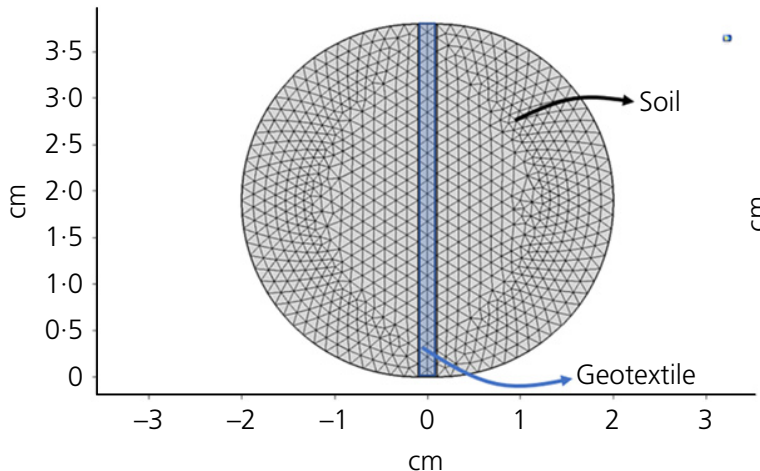

(a)

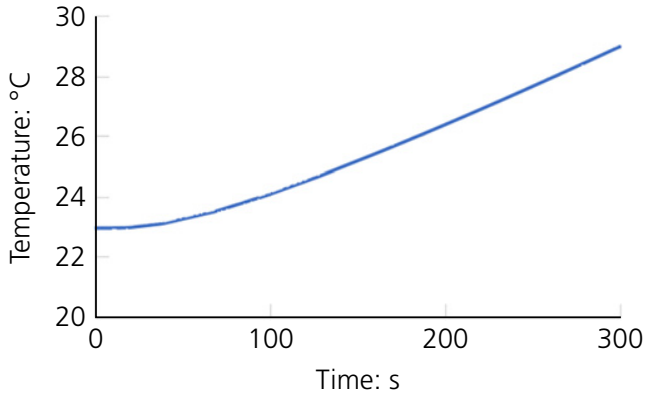

(c) be sufficient to maintain the initial steep heating rate and thus to reach higher temperatures. In addition, the heat loss through the boundary of the container could have prevented further temperature rise after reaching thermal equilibrium between the soil and the surrounding air. The slim difference in the temperature rise between the sand and clay specimens suggests that their thermal properties are similar and thus there is no significant difference in the heat propagation as long as the soils are dry.

Another set of tests was conducted with different geotextile types to confirm the fixation of MNPs to the geotextile (Fig. 6(b)). As could be expected, the non-woven geotextile (with a rough surface) showed a continuous temperature increase while the woven one (with a smooth surface) resulted in less increase. This implies that the fixation of MNPs to the geotextile surface is affected by the surface roughness. In other words, the structural complexity may contribute to a greater amount of MNP fixation by physically trapping the particles. Therefore, with increasing roughness of the geotextile surface, firmer entrapment of the synthesised MNPs is induced, and thus greater heating performance is achievable.

Note that the MNP-coated geotextile was heated up to $60^{\circ} \mathrm{C}$ in less than $1 \mathrm{~min}$ when exposed to the alternating magnetic field without surrounding soil. Therefore, the heat transfer to the surrounding soil also prevents extreme heating of the geotextile, which helps not only to warm up the surrounding soil, but also to hinder mechanical deterioration of the geotextile.

\section{INVERSE ANALYSIS FROM NUMERICAL SIMULATION,} ENERGY EFFICIENCY AND FIELD APPLICATION

The heat flux generated by the MNP-coated geotextile was difficult to measure in a precise way due to the heat loss to the surroundings. For this reason, complementary numerical 
Table 2. Properties of the soil and geotextile used in the simulation

\begin{tabular}{l|c|c}
\hline Property & Soil* & $\begin{array}{c}\text { MNP-coated } \\
\text { geotextile }\end{array}$ \\
\hline Density: $\mathrm{kg} / \mathrm{m}^{3}$ & 1400 & 940 \\
Thermal conductivity: W/(m K) & $0 \cdot 27$ & $0 \cdot 27$ \\
Specific heat capacity: $\mathrm{J} /(\mathrm{kg} \mathrm{K})$ & 800 & 800 \\
\hline
\end{tabular}

*Soil properties are adapted from Hamdhan \& Clarke (2010).

simulations were conducted to estimate the intensity of soil heating through the heating of MNP-coated geotextile inversely, by comparing the results with the experimental data. A two-dimensional (2D) cross-sectional model was generated using Comsol Multiphysics to simulate the heating of geotextile and the heat propagation through the surrounding soil medium (Fig. 7(a)). In the simulation model, the MNP-coated geotextile was located in the middle and was surrounded by soil to emulate the central part of the experimental set-up. The properties of soil and geotextile used in the simulation are summarised in Table 2. Other than the density, other parameters of the geotextile were the same as those of soil for simplicity. The initial temperature of the soil and geotextile was set to $T_{0}=23^{\circ} \mathrm{C}$, and the outside of the soil was set as an open boundary. The total simulation time was $300 \mathrm{~s}$. During the simulation, a constant heat rate, $Q_{0}=P_{0} / V$, was applied to the geotextile located in the middle to mimic the electromagnetic heating of it. Different values of heating rate were applied during different implementations until the simulation result resembled the experimental data. Figure 7(b) shows the simulation result when $P_{0}=40 \mathrm{~W}$ was applied to the nanoparticle-coated geotextile. With that input, the temperature-rise in the middle of the soil specimen after $300 \mathrm{~s}$, agreed well with the experimental measurement (Fig. 7(c)). Therefore, a first-order estimate is that the MNP-coated geotextile heated at a rate of around $40 \mathrm{~W}$ in the experimental set-up described earlier, which resulted in $\sim 10$ and $\sim 6^{\circ} \mathrm{C}$ of thermal increase in the geotextile and middle of the soil specimen, respectively. For comparison, another set of numerical simulations were conducted in which the geotextile was heated at the same heating rate, but without being surrounded by soil. In this case, the resultant heat increase was about $200^{\circ} \mathrm{C}$ after $300 \mathrm{~s}$ (Fig. 7(d)). Again, this shows that the presence of the soil plays a significant role in absorbing the heat generated in the geotextile, thereby preventing its deterioration.

The calculated absolute energy efficiency of the system seems very low $(<1 \%)$. For instance, energy input to run the induction heating system for $300 \mathrm{~s}$ was $E_{\text {input }}=2058 \mathrm{~W} \times$ $300 \mathrm{~s} \cong 617 \mathrm{~kJ}$. The approximate value of heat energy absorbed by the soil mass would be $E_{\text {soil }}=800 \mathrm{~J} /(\mathrm{kg} \mathrm{K}) \times$ $112.8 \mathrm{~g} \times 7 \cdot 3^{\circ} \mathrm{C} \cong 659 \mathrm{~J}$, using the average of the temperature measured on the top surface of the soil mass at $300 \mathrm{~s}$. This makes the energy efficiency $=659 \mathrm{~J} / 617 \mathrm{~kJ}=0 \cdot 11 \%$. Considering that significant heat loss would occur at the surface of the soil mass to the surroundings, the actual energy efficiency is expected to be greater than this calculated value. If one uses the simulation results, the estimated energy efficiency is $4-5 \%$. The overall energy efficiency could be improved if an induction heating system requiring less power could be used.

To scale-up for field application, securing a reliable source of magnetic fields with effect over a greater distance would be a top priority. The high intensity of the alternating magnetic fields could be achieved efficiently using the coil-style system, as was done in this study. With that, locating multiple arrays or stacking the coils around the
MNP-coated geotextile (i.e. embedded altogether underground) could be a possible configuration to deliver higher-intensity magnetic fields. The coils could also be used to approach the ground surface vertically above the buried MNP-coated geotextiles (e.g. a few centimeters away from the surface). Although the intensity of magnetic fields would be lower due to the longer distance, the simple underground installation and flexibility of heating a spot from the ground surface would be beneficial. A more systematic study is needed to address the field application of soil heating using these MNP-coated geotextiles and to achieve electromagnetic heating at practical cost and energy efficiency.

\section{CONCLUSIONS}

The presence of MNP-coated geotextiles was verified by way of microscopic observation and by the electromagnetic soil heating performance. Needless to say, the soil with the MNP-coated geotextile showed noticeable temperature increase immediately after being exposed to the alternating magnetic field. Although the heating trend was nearly the same between soil and clay, the surface roughness of the geotextile was found to be directly correlated with the soil heating performance. This affected the number of MNPs fixed to the geotextile surface. More in-depth and parametric studies of the optimum amount of MNPs, different soil moisture conditions, intensity of the magnetic field, field-scale applications and supporting numerical simulations would help to promote broader application of the proposed idea for various civil engineering practices.

\section{ACKNOWLEDGEMENTS}

The authors appreciate the generous donation of geotextiles by Tencate Geotextile, and they thank Dr. Sarah Kiemle and Louis Raboin for their assistance with the SEM and TEM measurements. The authors acknowledge Nebraska Center for Materials and Nanoscience and also thank Dr. Wen Qian for assistance with the VSM equipment.

\section{REFERENCES}

Benli, H. \& Durmus, A. (2009). Evaluation of ground-source heat pump combined latent heat storage system performance in greenhouse heating. Energy Build. 41, No. 2, 220-228.

Bera, A. \& Babadagli, T. (2015). Status of electromagnetic heating for enhanced heavy oil/bitumen recovery and future prospects: a review. Appl. Energy 151, 206-226.

Carpenter, D., Zhang, M., Stewart, M. A. \& McCartney, J. S. (2015). Pullout device for nonisothermal response of reinforcing geosynthetics in thermally-active geotechnical systems. In Conference proceedings of geosynthetics 2015 (eds J. A. McKelvey and J. S. McCartney), pp. 1-9. Portland, Oregon, USA: Industrial Fabrics Association International.

Coccia, C. J. R., Casady, A. \& McCartney, J. S. (2013). Physical modeling of the mechanical improvement of unsaturated silt through heating. In Proceedings of the 1st Pan-American conference on unsaturated soils (eds B. Caicedo, C. Murillo, L. Hoyos, J. E. Colmenares and I. R. Berdugo), pp. 141-146. London, UK: CRC Press.

Falciglia, P. P., Urso, G. \& Vagliasindi, F. G. A. (2013). Microwave heating remediation of soil contaminated with diesel fuel. J. Soils Sediments 13, No. 8, 1396-1407.

Glendinning, S., Jones, C. J. F. P. \& Pugh, R. C. (2005). Reinforced soil using cohesive fill and electrokinetic geosynthetics. Int. J. Geomech. 5, No. 2, 138-146.

Hamdhan, I. N. \& Clarke, B. G. (2010). Determination of thermal conductivity of coarse and fine sand soils. Proceedings world geothermal congress 2010 (ed. R. N. Horne), pp. 25-29. Bali, Indonesia: International Geothermal Association.

Heron, G., Van Zutphen, M., Christensen, T. H. \& Enfield, C. G. (1998). Soil heating for enhanced remediation of chlorinated 
solvents: a laboratory study on resistive heating and vapor extraction in a salty, low-permeable soil contaminated with trichloroethylene. Environ. Sci. Technol. 32, No. 10, 1474-1481.

Hu, L., Li, H. A., Babadagli, T. \& Ahmadloo, M. (2017). Experimental investigation of combined electromagnetic heating and solvent-assisted gravity drainage for heavy oil recovery. J. Petrol. Sci. Engng 154, 589-601.

Javaid, A., Bajwa, R. \& Anjum, T. (2008). Effect of heatsterilization and EM (effective microorganisms) application on wheat (Triticum aestivum L.) grown in organic-amended sandy loam soil. Cereal Res. Commun. 36, No. 3, 489-499.

Jordan, A., Scholz, R., Wust, P., Fahling, H. \& Felix, R. (1999). Magnetic fluid hyperthermia (MFH): cancer treatment with AC magnetic field induced excitation of biocompatible superparamagnetic nanoparticles. J. Magn. Magn. Mater. 201, No. 1-3, 413-419.

Liew, R. K., Nam, W. L., Chong, M. Y., Phang, X. Y., Su, M. H., Yek, P. N. Y., Ma, N. L., Cheng, C. K., Chong, C. T. \& Lam, S. S. (2018). Oil palm waste: an abundant and promising feedstock for microwave pyrolysis conversion into good quality biochar with potential multi-applications. Process Saf. Environ. Prot. 115, 57-69.

Omer, A. M. (2008). Ground-source heat pumps systems and applications. Renewable Sustainable Energy Rev. 12, No. 2, 344-371.

Popplewell, J. \& Sakhnini, L. (1995). The dependence of the physical and magnetic properties of magnetic fluids on particle size. J. Magn. Magn. Mater. 149, No. 1-2, 72-78.

Rodriguez-Chueca, J., Mediano, A., Ormad, M. P., Mosteo, R. \& Ivelleiro, J. L. (2014). Disinfection of wastewater effluents with the Fenton-like process induced by electromagnetic fields Water Res. 60, 250-258.

Roland, U., Buchenhorst, D., Holzer, F. \& Kopinke, F. D. (2008). Engineering aspects of radio-wave heating for soil remediation and compatibility with biodegradation. Environ. Sci. Technol. 42, No. 4, 1232-1237.
Stewart, M. A., Coccia, C. J. R. \& McCartney, J. S. (2014a). Issues in the implementation of sustainable heat exchange technologies in reinforced, unsaturated soil structure. In Proceedings of GeoCongress 2014 (eds M. Abu-Farsakh and L. Hoyos), pp. 4066-4075. ASCE, Reston, VA, USA

Stewart, M. A., Coccia, C. J. R. \& McCartney, J. S. (2014b) Physical modeling of the thermal-hydro-mechanical response of a thermally active soil-geosynthetic system. In Proceeding of the 10th international conference on geosynthetics (eds M. Ziegler, G. Brau, G. Heerten and K. Laackmann), vol. 1, pp. 232-239. DGGT, Berlin, Germany.

Trevors, J. T. (1996). Sterilization and inhibition of microbial activity in soil. J. Microbiol. Methods 26, 53-59.

Varanasi, P., Fullana, A. \& Sidhu, S. (2007). Remediation of PCB contaminated soils using iron nano-particles. Chemosphere $\mathbf{6 6}$ No. 6, 1031-1038.

Wang, P., Limpens, J., Mommer, L., van Ruijven, J., Nauta, A. L., Berendse, F., Schaepman-Strub, G., Blok, D., Maximov, T. C. \& Heijmans, M. M. P. D. (2017). Above- and below-ground responses for four tundra plant functional types to deep soil heating and surface soil fertilization. J. Ecol. 105, 947-957.

Zhang, L., Xu, P., Mao, J., Tang, X., Li, Z. \& Shi, J. (2015). A low cost seasonal solar soil heat storage system for greenhouse heating: design and pilot study. Appl. Energy 156, 213-222.

Zhang, C., Liu, J., Guo, S., Xiao, S., Shen, Z. \& Xu, L. (2018) Comparison of microwave and conventional heating methods for oxidative stabilization of polyacrylonitrile fibers at different holding time and heating rate. Ceram. Int. 44, No. 12, $14377-14385$

Zhu, H., He, J., Hong, T., Yang, Q., Wu, Y., Yang, Y. \& Huang, K. (2018a). A rotary radiation structure for microwave heating uniformity improvement. Appl. Therm. Engng 141, 648-658.

Zhu, J., Yang, Z., Li, X., Qi, S. \& Jia, M. (2018b). Application of microwave heating with iron oxide nanoparticles in the in situ exploitation of oil shale. Energy Sci. Engng 6, No. 5, $548-562$. 